\title{
EDITORIAL
}

Shape Memory and Superelastic Technologies 2008

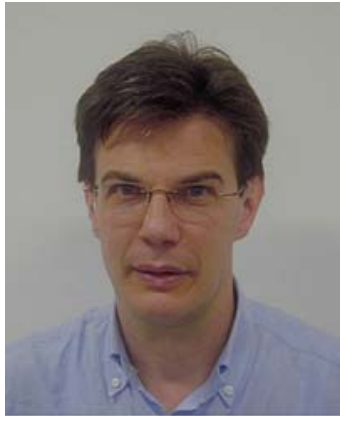

Ausonio Tuissi

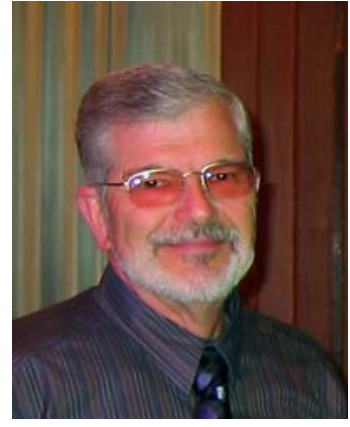

M.R. Mitchell

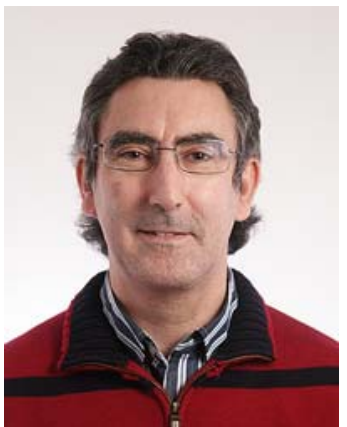

José San Juan

The International Conference on Shape Memory and Superelastic Technologies-SMST 2008 - took place in Stresa (Maggiore Lake), Italy, 21-25 September 2008. It was sponsored by the SMST International Organization, an affiliate society of ASM International, and locally endorsed by CNR IENI (Lecco) an Institute of the National Research Council of Italy.

As was the case for previous SMST conference editions, SMST 2008 was dedicated to the technical/ scientific aspects and applications of Shape Memory Alloys. The specific scopes of SMST 2008 were directed toward a better, deeper, and shared understanding of the interplay between the most recent developments in SMA research and the positioning of applications of SMA on the market place. The conference program included approximately 160 presentations arranged in 19 oral and 2 poster sessions during which lively discussions of overall participation was appreciated. A positive atmosphere was also created in the "Product Exhibition" of SMA companies, "R\&D exhibition" for research centers and "Workshop on SMA" conference events. The strong and widespread interaction between academic, government and industrial enterprises operating worldwide in the field of SMA and sharing their knowledge and experience represented the main result of that event.

We would like to acknowledge the members of the organizing and advisory committees, the sponsors, the session chairs, the event chairs and particularly CNR IENI and ASM staff members. The success of SMST 2008 was only possible through their generosity and hard work.

This special issue of the Journal of Materials Engineering and Performance (JMEP) features a selection of contributions presented at SMST 2008. Authors of the selected articles were invited to submit their manuscripts to JMEP where they passed through the full peer review process required for publishing refereed papers. These 63 selected papers represent the broad cross-section of the topics covered at the conference and provide the latest scientific and engineering developments in the exciting field of applied shape memory materials.

\author{
Ausonio Tuissi \\ SMST 2008 Chairman \\ National Research Council of Italy \\ CNR IENI, Lecco, Italy
}

\section{M.R. Mitchell}

SMST Organization President

Northern University of Arizona

Mechanical Engineering Department

José San Juan

SMST 2008 Technical Program Chair

University of the Basque Country

Dpt. Physics of Condensed Matter (Bilbao), Spain 